Upsala J Med Sci 99: 69-71, 1994

\title{
Neonatal Polycythaemia in Down Syndrome
}

\author{
(Short communication)
}

\author{
G. Annerén
}

From the Departments of Clinical Genetics and Pediatrics, University Hospital, Uppsala, Sweden

Neonatal polycythaemia (NP) in Down syndrome (DS) was described in 1970 by Weinberger and Olenick (10) and is a well known feature of this chromosome disorder $(6,8,9)$. Miller and Cosgriff (8) found that, among the haematological abnormalities in newborn infants with DS, NP is the most common. The aim of the present study was to examine the natural history of NP in DS and to evaluate the clinical effects.

Of 67 newborn infants with DS, 46 were included in the study. Twenty-one infants had congenital malformations of the heart or of the gastrointestinal tract and were excluded. Thus, none of the included infants had any malformation of the heart or underwent any operation in the neonatal period that could have interfered with the level of the erythrocyte volume fraction (EVF) or the clinical status.

The mean birth weight $( \pm 1 \mathrm{SD})$ was $3.08 \pm 0.05 \mathrm{~kg}$ and the mean gestational age $( \pm 1$ SD) was $38.4 \pm 1.5$ weeks. The EVF levels (Coulter counter haematocrits) of capillary blood of the DS infants were compared with the normal range (mean $\pm 3 S D$ ) during the first 10 days presented by Gatti (5) (Fig. 1). In 13 of the DS infants the EVF levels from capillary blood were compared with that from central venous blood.

The central venous EVF levels correlated well with the capillary EVF levels $(r=0.7)$, and were $8 \%$ lower than the peripheral EVF levels. The mean EVF level at birth was $78 \%$ (range $62-90 \%$ ). Thirtysix of the 46 infants had EVF $>70 \%$, and all but one had EVF $>65 \%$. The individual EVF levels are depicted in Fig. 1 . In 12 of the infants the EVF levels were followed for 1-3 weeks and remained increased compared with those of healthy infants (Fig. 1).

The mean heart rate $( \pm 1$ SD) at the age of $12-24$ hours was $122 \pm 11 / \mathrm{min}$ and the mean respiratory frequency $( \pm 1 \mathrm{SD})$ was $44 \pm 4 / \mathrm{min}$. The heart and respiratory rates did not differ significantly from those in heal thy newborn infants. The EVF level showed no correlation to gestational age or birth weight.

Nineteen of the 46 children $(41 \%)$ had serum bilirubin levels $>300 \mathrm{umol} / 1$ and were treated with light therapy on the basis of non-physiological jaundice (Fig. 1). None of the children had $\mathrm{Rh}$ or $\mathrm{ABO}$ immunization. The percentage number of reticulocytes was compared with the normal range (4). The reticulocyte levels in 21/31 newborn infants with DS were above the upper normal limit (Fig. 2). 

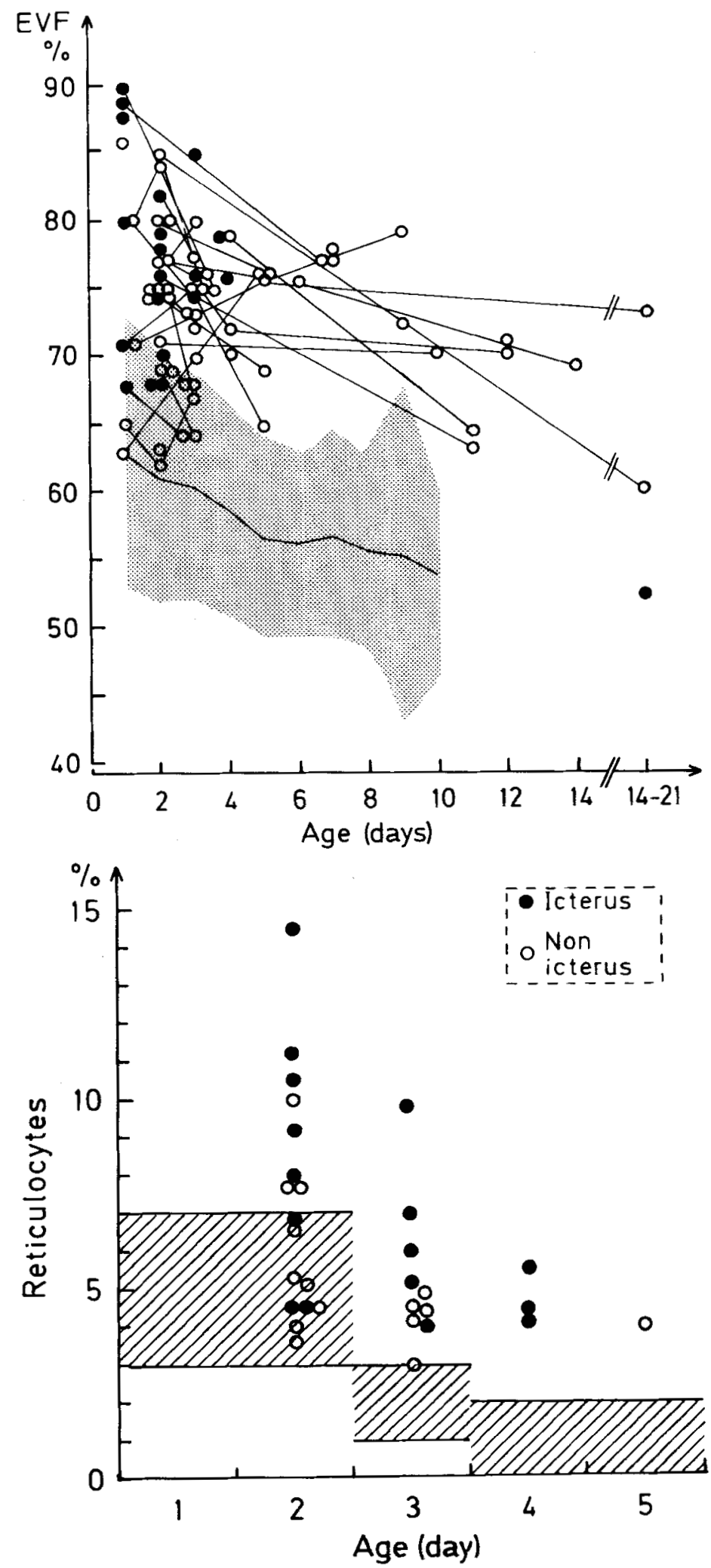

Figure 1 Haematocrit levels in 46 newborn infants with Down syndrome, without congenital malformation of the heart or gastrointestinal tract, compared with the normal range (mean \pm 3 SD; J Pediatr 1967;70:117-119). The development of the haematocrit levels from day 1 to day 21 is depicted in the figure. Infants who were treated with light therapy because of nonphysiological jaundice (serum bilirubin $>300$ umol/l) are indicated with filled circles.

Figure 2 Percentage numbers of reticulocytes in 31 newborn infants with Down syndrome, without congenital malformation of heart or gastrointestinal tract, in relation to the normal range. Infants who were treated with light therapy because of nonphysiological jaundice (serum bilirubin $>300$ umol/1) are indicated with filled circles. 
This study has shown that almost all infants with DS have NP. In spite of a sometimes extremely elevated haematocrit, no signs of harmful effects of the increased blood viscosity were observed. This is remarkable since it is reported that haematocrit above 65 implies such an in increase in viscosity that it will have a harmful effect on the newborn child (7). NP has been associated with reduced brain flow and symptoms of central nervous dysfunction in the neonatal period and lower achievment and IQ scores at school age. Although these findings should be interpreted with caution, one might argue that polycethaemic infants, in particular those with DS, should be treated with haemodilution.

The cause of NP in DS is unknown. It is not an effect of a congenital malformation of the heart, since all children with such malformations were excluded from this study. The serum erythropoietin levels in ten of the infants, determined by standard radioimmunoassay, were within the normal range and hardly detectable two days after birth. The gene of erythropoietin is mapped on chromosome 7 and thus the trisomy 21 state of the infants with DS cannot have any primary gene dosage effect upon the level of erythropoetin. It seems reasonable to assume that there is a still unknown haematopoietic growth factor mapped on chromosome 21 , which acts in the fetal and neonatal period (2). This growth-regulating factor might not only be responsible for the transient NP, but also for the transient neonatal megakaryoblastic leukaemia, which is 20 times more common in infants with DS than in healthy children $(1,3)$.

\section{REFERENCES}

1. Engel R.R., Hammond D., Eitzman D.V., Pearson H. \& Krivit W.: Transient congenital leukemia in 7 infants with mongolism. J Paediatr 65: 303-305, 1964.

2. Epstein C.J.: The consequences of chromosome imbalance, Principles mechanisms and models, New York; Cambridge University Press. 1986.

3. Fong C-t. \& Brodeur GM.: Down's syndrome and leukemia: Epidemiology, Genetics, Cytogenetics and Mechanisms of Leukemogenesis. Cancer Genetics and Cytogenetics 28: $55-76,1987$.

4. Gairdner D. \& Marks J.: Blood formation in infancy II. Normal erythropoiesis. Arch Dis Childh 27: 214-223, 1952.

5. Gatti R.A.: Hematocrit values of capillary blood in newborn infants. J Paediatr 70: $117-119,1967$.

6. Lappalainen J. \& Kouvalainen K.: High hematocrits in newborns with Down's syndrome. A hitherto undescribed findng. Clin Pediatr 11: 472-474, 1970.

7. Mackintosh T.F. \& Walker C.H.M.: Blood viscosity in the newborn. Arch Dis Childh 48: 547-53, 1973.

8. Miller M. \& Cosgriff J.M.: Hematological abnormalities in newborn infants with Down syndrome. Am J Med Genet 16: 173-177, 1983.

9. Smith G.F. \& Berg J.M.: In "Down's anomaly" Ed 2, New York: Churchill-Livingstone, pp 100-110, 1976.

10. Weinberger M.W. \& Oleinick A.: Congenital marrow dysfunction in Down's syndrome. J Paediatr 77: 273-9, 1970.

Address for reprints: Göran Annerén, M.D. Department of Clinical Genetics University Hospital

S-751 85 Uppsala

SWEDEN. 